\title{
Research and Finding Technical Enablers using Ism for Industry 4.0 in Indian Agricultural Industries
}

\author{
Balasubramanian.S, Hari Sankar.R
}

\begin{abstract}
At the present scenario, agriculture industries are working hard to produce farmer satisfied products at affordable cost. The globalization and heavy worldwide competition stress them to precise and sustain in the market. The existing system are to be modified for smart manufacturing to cop up international benchmarking. The modifications consist of modern machine tools, automation system, machine learning technologies and systematic approach. The existing system and path for every individual industry are unique. Here the skill needed is to fit suitable enablers to the factors. The enactment of Industry 4.0 appropriately to industry is a task, because different industries lie at different sectors. In this context a study is carried to identify the important technological enablers for the enactment of Industry 4.0 in Indian agricultural industries. Various enablers essential for implementing Industry 4.0 has been identified from literature review. The Interpretive structural modelling(ISM) is employed for finding the mutual relationship among the enablers. Data collected to rank the enablers in the agricultural field. The technological enablers are further being classified as dependent and driving factors. Thus a hypothetical model is created based on literature review. A proper acknowledgement of interactions among enablers will help organization to rank the factors and manage these factors with more efficiency to produce advantages of implementing Industry 4.0. This paper is aiming to identify the various enablers to implement Industry4.0 in Indian industries.
\end{abstract}

Keywords: Industry4.0, Farmer satisfied product, Affordable cost, Technical enablers, ISM.

\section{INTRODUCTION}

Industrialization began in Indian agricultural field with the introduction of tractors in 1970s.Introduction of tractors marked for the major revolution in agricultural field. Subsequently with introduction of electricity many electric powered devices like motors, pumps came into agricultural field and marked the sustainable agricultural movement. The modern era of agricultural industry came with automation through high level machineries and robots. Nowin the developed countries a world of industry 4.0, in which computers and automation will come in a better way.The robotics integrated with computer systems equipped with high end machine learning algorithms, which will control robotics with minimum human effort [1]. Moreover, industry4.0 and its present concepts (i.e Smart Factory, Cyber-Physical System, Internet of Things (IOT) and Internet of Services (IOS)) will result in a paradigm shift in work organization, its business models and production

Revised Manuscript Received on September 10, 2019.

Balasubramanian.S, Department of Mechanical Engineering, Kumaraguru College of Technology, Coimbatore, Tamilnadu, India.

(E-mail: balasubramanian.s.mec@kct.ac.in)

Hari Sankar.R, Department of Mechanical Engineering

Kumara guru College of Technology, Coimbatore, Tamilnadu, India.

(E-mail: hari.17mie@kct.ac.in) technology [2]. The industry in future have to be efficient, structured,interconnectedand real time oriented in service. Thus, the future agricultural industries have to deal with large volume of digital data and information.By collecting and processing the product and quality information,the smart product concept will aid in automatic monitoring and context awareness which lead to performance improvement in various IT systems across levels up to the Enterprise Resource Planning system. Both Production and quality management could make use of the fresh information and data for better decision-making and evaluation of organization's activities. It will also help in ensuring the modern quality management idea,which preaches to ensure maximum efficiency with high performance of all process along with cutting down the number of defectives. Adoption of Industry 4.0, makes it possible conserve India's competitive advantage in agricultural industry and make a sustainable working environment with highly skilled workers to support large scale customization.

Though Industry4.0 will come into reality with few years from now, this research article takes a small effort in helping small scale agriculture industries to identify and prioritize the right enablers and assist them in providing better solutions [3] for day to day problems and in turn leading them to think Industry4.0.The main objective of this paper is to identify the important enablers for industry 4.0 with respect to Indian Agricultural Industry and the relationship between them.

The objective of this research is:

To identifying and ranking the enablers those are significant for the enactment of industry 4.0 in Indian Agricultural industries.

To establish the relation among the identified enablers.

To enlarge a structural replica using the ISM (Interpretive structural modelling).

After conducting analysis work the next step of objective was to identify day to day problems in an agricultural industry and implement smart solutions in a way to sustain them temporarily, but to fire up the next industrial revolution by using the enablers that are identified in literature review and encourage the top level management to withstand with global level competition and understand importance of industry 4.0.

An enabler may be most suitable for agriculture industry and the same is less important to a process or service industry. The methodology ISM is used to resolve this problem. The following section discuss the identification of

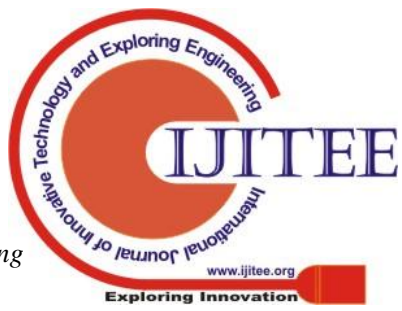


important enablers for the enactment of the Industry 4.0 in the Indian agricultural industry, which is proceeded with the structural model of enablers in form of diagraph to create a clear picture of their dependence. Finally, the conclusion of research work has been presented.

\section{IDENTIFICATION OF VARIABLES TO INDUSTRY 4.0 IMPLEMENTATION}

\section{A. Big Data}

The effect of creating the IOT and big data is the excogitation of Industry4.0. Agricultural Industry big data generated by inter communication with agricultural and technical departments, multisource inputs, feedbacks from farmers and other external-related information, might cater to most of the problems with new effective solutions thus increase the productivity. The industrial big data implementation can assist the storage systems to store information and data for a very long period of time, the data can be made possible easily at any point in the future. The data include customer feedbacks to various machineries and other products, cost of machineries, maintenance and other service details etc. A smart factory can operate using hightech sensors and advanced information technologies, thus the large volume of data is produced and gathered in a smart factory. Industrial big data is considered to have " $5 \mathrm{~V}$ " characteristics, that is, volume, velocity, variety, veracity and value, this made it difficult for traditional storage and processing system to handle Industrial Big data. Industrial Big data depicts a clear picture of a production process [4].

\section{B. Product Life Cycle Management}

Inter-linked product life cycles can only benefit as base element in value creation networks in Industry4.0. Product life cycle management is the process of controlling the entire cycle of the product from its idea generation stage to design,manufacture and to service and disposal of product. The enactment of industry 4.0 will aid in a better of integration. Industry 4.0 will ensure the customer participation in production and design process, it will help the industry to satisfy the customer requirements and withstand competition. The agro industry can take the innovative machineries, like garden tiller, palm climber etc.

By involving customer opinions in product life cycle management the industry can maximize its profit also.

\section{Networked Service System}

Connecting the maintenance department and machine using customer via a network allow them to interact and collaborate effectively. By establishing a network service system, a complete over view of machineries can be obtained, even the frequently occurring problems in each of the machines can be found out. Moreover, farmers can easily report the machine complaints in network system. The maintenance or service engineers can prescribe solution even through online system [5].

\section{Top Level Management}

The main objective of top level management is to improve the productivity and quality of the products offered to the customers. Management techniques like TPM, TQM advices from the farmers on the need for developing new

and QFD are applied for achieving management's aim. Top level management involvement is one of the essential factor in determining the success of Industry 4.0. Top level management provides guidance and support to information system activity. Top level management emancipate workers to assume the responsibility of problems or opportunities and to be visionary in enactment of improvements and to make strategic decisions in best interest of industry.

\section{E. Mass Customization}

The benefits of customization are not only gaining customer support but also improving productivity of organization. Farmers in same area have different terrain agricultural lands so they need machineries that are apt for their lands. Many farmers practice mixed cropping and crop rotation in their farm lands, so the machineries for the particular crop should be made available at the its time of cultivation. If a single machine can be used for many purposes (multipurpose machines) like ploughing,weed removal, levelling etc., such machines should be promoted.

\section{F. Supply Chain Management(SCM)}

SCM is a value creation process involving many units, entities. Industry 4.0 ensures the company can create value based on its competence in making market strategies and to react to global competition by utilising the internal resources and skills.

\section{G. Operational Efficiency}

The high-tech digital technologies in Industry 4.0 can recommend new methodologies as solution for dealing with hardships and raising the operational efficiency. Digitalization have introduced smart phones across population in India, through these smart phones farmers can communicate with the customer service department of company through an android application. Farmers can even register their feedbacks and other suggestion through a tollfree number, even farmers who does not have a smart phone can make use of the service. By these small steps operational efficiency in the industry can be improved.

\section{H. Internet of Things and Services(IOT)}

The most propitious technologies of industry 4.0 are IOT and IOS. They are based on the development of smart factories and smart services implanted in an internet service.IOT benefits the industry oriented items like machines,raw materials, workers,supply chain, farmers and production line to be connected, which means necessary items can exchange information and control activities autonomously and solitarily.IoT act as the backbone to incorporate machines, products, human factors, information systems,production lines and systems across organizational boundary to form a new efficient, interconnected and agile value chain. IoT can aid in storing details about the customers who take machines on lease.It can also serve as an online platform for booking machineries and for purchasing other products. IoT is one of the four major components of industry 4.0 as identified by Hermann et al [8]. 


\section{Professional training and development}

This department measure and analyse the current skills of work force and implement methodologies to improve their skill and competencies. Employees are trained to adapt with the changes in technology and their work environment. Thus motivating them to develop new skills to get well prepared with digital workplace. Training department also give intense training to heavy machine operators and they issue license for qualified operators. Training and development department provide $\mathrm{s}$ training for farmers also. Farmers trained in identifying the problems with machines and they are also trained for providing minor repair works.

\section{J. Collaborative Productivity}

The vision of industry 4,0 is to improve the collaborative productivity across the various departments in the industry and thereby leading them to be a better competitive industry.

The important target in increasing collaborative productivity is to lower the costs involved in production by cutting down the wastage of resources. Modification of the manufacturing process also result in raising collaborative productivity. Replacing the old manual tool set with new pneumatic tool set reduce the time and effort in maintenance activities.

\section{K. Visual Computing}

Visual computing technologies could act as a connective factor in many applications related to Industry 4.0 and industrial internet. Visual computing is the process in which the field of obtaining, examining and synthesizing optical data by way of computers that create available relevant to the field tools. Visual computing valuable assistance for new initiatives as in case of German vision of industry 4.0. Farmers can learn the operation of machineries through smart phone applications like YouTube or WhatsApp, even they can report the malfunctioning through videos via these smart phone applications.

\section{INTERPRETATIVE STRUCTURAL MODELLING}

ISM is an established methodology for identifying relationships among specific items, which result in a problem or in an issue. Any major problem under consideration, a number of factors may be related to an issue or a problem. However, the direct and indirect relationships between the factors describe the situation for more clearly than the individual factors taken into isolation. In this technique a set of different direct and indirect elements are structured into a comprehensive structured model [6]. The model so framed depicts the structure of a complex issue or problem in a carefully designed pattern.

ISM is a process that helps to develop a model of the complex relationships between the many factors involved in a complex situation. This segment deals with the conversation of ISM method.

The various steps involved in ISM methodology are as follows:

Step 1: The variables which manipulate the method are listed. In this investigate work enablers in performance of Industry 4.0 in the Indian Agro Industry have been identified as variables.
Step 2: The enablers well-known in the before steps are used to find out the contextual connection along with enablers.

Step 3: A structural self-interaction matrix (SSIM) is developed for the enablers to show the pair wise relationship among enablers of the system.

Step 4: From the SSIM a reachability matrix is developed and the obtained matrix is checked for transitivity, which is an assumption made in ISM, i.e, if a variable $\mathrm{A}$ is related to variable $B$ and variable $B$ is related to the variable $C$, then variable A necessarily is related to variable $C$.

Step 5:A partition of the reach ability matrix is done into different levels after being obtained from step 4 .

Step 6: One directed graph is drawn based on the contextual relationships in the reach ability matrix, and the transition links are removed.

Step 7: The diagraph that is obtained is improved into an Interpretive Structural representation by replacing nodes of the enablers with the statements.

\section{STRUCTURAL SELF-INTERACTION MATRIX AND REACH ABILITY MATRIX}

The enablers of the system are identified relevant to the problem and the significant enablers are selected from the group using techniques such as brainstorming sessions with experts [7]. On the basis of literature review for Industry 4.0,11 significant enablers were identified.

The next step in this methodology is to analyze and find out the contextual relationship between the enablers. The relationship thus identified among enablers is based on the pair of the variables that are examined. Thus a matrix is developed based on the expert opinions and dependencies. The next step is to form a SSIM.Four symbols are used for the direction of relationships between the enablers ( $i$ and $j$ ):

$\mathrm{V}$ : If enabler $\mathrm{i}$ lead to enabler $\mathrm{j}$ but if both the enablers are not interdependent;

A: If enabler $\mathrm{j}$ leads to enabler $\mathrm{i}$ but if both the enablers are not interdependent;

$\mathrm{X}$ : If both the enablers are interdependent;

$\mathrm{O}$ : Both the variables are unrelated;

For example, variable $\mathrm{V}$ is mentioned in the cell $(1,11)$ because variable 1 leads to variable 14 . In the same way, variable $\mathrm{A}$ is mentioned in the cell $(2,10)$ because variable 2 is driven by variable 10.Similar method is adopted for filling the SSIM table with appropriate variables and tabulated in Table 1 .

After the SSIM is formed with the help of the above variables, the SSIM table is converted to a binary matrix called as initial reachability matrix, where the variables $\mathrm{V}$, $\mathrm{A}, \mathrm{X}$, and $\mathrm{O}$ in the matrix are substituted with numbers 1 and 0 based on the subsequent rules:

If the value in the cell $(i, j)$ is $V$, then the $(i, j)$ value in the reach ability matrix will be 1 and $(\mathrm{j}, \mathrm{i})$ value will be 0 ; for $\mathrm{V}$ $(1,11)$ in SSIM, ' 1 ' has been given in cell $(1,11)$ and ' 0 ' in cell $(11,1)$ in preliminary reach ability matrix.

If the value in the cell $(i, j)$ is $A,(i, j)$ value in the reach ability matrix will be 0 and $(j, i)$ value will be 1 ; for $A(1,10)$ 
in SSIM, ' 0 ' has been given in cell $(1,10)$ and ' 1 ' in cell $(10,1)$ in preliminary reach ability matrix.

If the value in the cell $(i, j)$ is $X,(i, j)$ value in the reach ability matrix will be 1 and $(\mathrm{j}, \mathrm{i})$ value will also be 1 ; forX $(1,2)$ in SSIM, ' 1 ' has been given in cell $(1,2)$ and ' 1 ' in cell $(2,1)$ also in preliminary reach ability matrix.

If the value in the cell $(i, j)$ is $X,(i, j)$ value in the reach ability matrix will be 0 and $(j, i)$ value will also be 0 ;

The final reach capability matrix is then obtained by incorporating the transitivity as discussed in the ISM method. The initial and ultimate reach facility matrix has been shown in Table 2 and Table 3.

Table I: Structural Self-Interaction Matrix

\begin{tabular}{|c|c|c|c|c|c|c|c|c|c|c|c|}
\hline Variables & 11 & 10 & 09 & 08 & 07 & 06 & 05 & 04 & 03 & 02 & 01 \\
\hline 1 & $\mathrm{v}$ & $\mathrm{v}$ & $\mathrm{v}$ & $\mathrm{x}$ & $\mathrm{v}$ & A & $\mathrm{v}$ & A & $\mathrm{v}$ & o & 0 \\
\hline 2 & o & $\mathrm{x}$ & A & A & $\mathrm{v}$ & A & $\mathrm{v}$ & A & $\mathrm{v}$ & o & o \\
\hline 3 & o & $\mathrm{v}$ & $\mathrm{x}$ & A & $\mathrm{V}$ & A & $\mathrm{v}$ & A & o & o & 0 \\
\hline 4 & o & o & $\mathrm{V}$ & o & $\mathrm{v}$ & $\mathrm{x}$ & $\mathrm{v}$ & o & o & o & o \\
\hline 5 & o & o & A & o & $\mathrm{v}$ & A & o & o & o & o & $\mathrm{O}$ \\
\hline 6 & o & o & $\mathrm{v}$ & o & $\mathrm{v}$ & o & $\mathrm{o}$ & o & o & o & $\mathrm{O}$ \\
\hline 7 & o & o & o & o & o & o & o & o & o & o & o \\
\hline 8 & o & $\mathrm{V}$ & $\mathrm{v}$ & o & $\mathrm{v}$ & A & $\mathrm{V}$ & $\mathrm{V}$ & o & o & o \\
\hline 9 & 0 & $\mathrm{O}$ & $\mathrm{O}$ & $\mathrm{O}$ & $\mathrm{V}$ & 0 & $\mathrm{O}$ & $\mathrm{O}$ & o & $\mathrm{O}$ & $\mathrm{O}$ \\
\hline 10 & o & o & A & o & $\mathrm{v}$ & A & $\mathrm{v}$ & $\mathrm{v}$ & o & o & $\mathrm{O}$ \\
\hline 11 & 0 & $\mathrm{v}$ & $\mathrm{V}$ & $x$ & $\mathrm{~V}$ & A & A & $\mathrm{V}$ & 0 & 0 & 0 \\
\hline
\end{tabular}

Table II: Initial Reachability Matrix

\begin{tabular}{|c|c|c|c|c|c|c|c|c|c|c|c|}
\hline Variables & 1 & 2 & 3 & 4 & 5 & 6 & 7 & 8 & 9 & 10 & 11 \\
\hline 1 & 1 & 1 & 1 & 0 & 1 & 0 & 1 & 1 & 1 & 1 & 1 \\
\hline 2 & 0 & 1 & 1 & 0 & 1 & 0 & 1 & 1 & 1 & 1 & 0 \\
\hline 3 & 0 & 1 & 1 & 0 & 1 & 0 & 1 & 0 & 1 & 1 & 0 \\
\hline 4 & 1 & 1 & 1 & 1 & 1 & 1 & 1 & 1 & 1 & 1 & 1 \\
\hline 5 & 0 & 0 & 1 & 0 & 1 & 0 & 1 & 0 & 0 & 0 & 0 \\
\hline 6 & 1 & 1 & 1 & 0 & 1 & 1 & 1 & 1 & 1 & 1 & 1 \\
\hline 7 & 0 & 0 & 0 & 0 & 0 & 0 & 1 & 0 & 0 & 0 & 0 \\
\hline 8 & 1 & 1 & 1 & 0 & 1 & 0 & 1 & 1 & 1 & 1 & 1 \\
\hline 9 & 0 & 1 & 1 & 0 & 1 & 0 & 1 & 0 & 1 & 1 & 0 \\
\hline 10 & 0 & 1 & 1 & 0 & 1 & 0 & 1 & 0 & 0 & 1 & 0 \\
\hline 11 & 1 & 1 & 1 & 0 & 1 & 0 & 1 & 1 & 1 & 1 & 1 \\
\hline
\end{tabular}

Table III: Final Reachability Matrix

\begin{tabular}{|c|c|c|c|c|c|c|c|c|c|c|c|c|}
\hline Variables & 1 & 2 & 3 & 4 & 5 & 6 & 7 & 8 & 9 & 10 & 11 & $\begin{array}{c}\text { Driver } \\
\text { power }\end{array}$ \\
\hline 1 & 1 & 1 & 1 & 0 & 1 & 0 & 1 & 1 & 1 & 1 & 1 & 9 \\
\hline 2 & 0 & 1 & 1 & 0 & 1 & 0 & 1 & 1 & 1 & 1 & 0 & 7 \\
\hline 3 & 0 & 1 & 1 & 0 & 1 & 0 & 1 & 0 & 1 & 1 & 0 & 6 \\
\hline 4 & 1 & 1 & 1 & 1 & 1 & 1 & 1 & 1 & 1 & 1 & 1 & 11 \\
\hline 5 & 0 & 0 & 1 & 0 & 1 & 0 & 1 & 0 & 0 & 0 & 0 & 3 \\
\hline 6 & 1 & 1 & 1 & 0 & 1 & 1 & 1 & 1 & 1 & 1 & 1 & 10 \\
\hline 7 & 0 & 0 & 0 & 0 & 0 & 0 & 1 & 0 & 0 & 0 & 0 & 1 \\
\hline 8 & 1 & 1 & 1 & 0 & 1 & 0 & 1 & 1 & 1 & 1 & 1 & 9 \\
\hline 9 & 0 & 1 & 1 & 0 & 1 & 0 & 1 & 0 & 1 & 1 & 0 & 6 \\
\hline 10 & 0 & 1 & 1 & 0 & 1 & 0 & 1 & 0 & 0 & 1 & 0 & 5 \\
\hline 11 & 1 & 1 & 1 & 0 & 1 & 0 & 1 & 1 & 1 & 1 & 1 & 10 \\
\hline Dependence & 5 & 9 & 10 & 1 & 10 & 2 & 11 & 6 & 8 & 9 & 5 & \\
\hline
\end{tabular}

\section{LEVEL PARTITIONS \& RESULTS}

From the final reach ability matrix, the reach ability set and the antecedence set can be obtained for each variable. consequently, the connection set of these sets have also been derived. The variables are given different levels in the ISM hierarchy based on their similarity between reach ability set and intersection set. From Table 4, level partition it has been seen that equipped efficiency has been found at Level 1 . The iteration has been continuous till the level of each variable has been identified and shown in table IV.

Table IV: Level Partitions

\begin{tabular}{|c|l|l|l|c|}
\hline Variables & \multicolumn{1}{|c|}{ Reachability set } & \multicolumn{1}{|c|}{ Antecedent set } & $\begin{array}{c}\text { Interaction } \\
\text { set }\end{array}$ & Level \\
\hline 1 & $1,2,3,5,7,8,9,10,11$ & $1,4,6,8,11$ & $1,8,11$ & VI \\
\hline 2 & $2,3,5,7,8,9,10$ & $1,2,3,4,6,8,9,10,11$ & $2,3,8,9,10$ & III \\
\hline 3 & $2,3,5,7,9,10$ & $1,2,3,4,5,6,8,9,10,11$ & $2,3,5,9,10$ & IV \\
\hline 4 & $1,2,3,4,5,6,7,8,9,10,11$ & 4 & 4 & VIII \\
\hline 5 & $3.5,7$ & $1,2,3,4,5,6,8,9,10,11$ & 3,5 & II \\
\hline 6 & $1,2,3,5,6,7,8,9,10,11$ & 4,6 & 6 & VII \\
\hline 7 & 7 & $1,2,3,4,5,6,7,8,9,10,11$ & 7 & I \\
\hline 8 & $1,2,3,5,7,8,9,10,11$ & $1,2,4,6,8,11$ & $1,2,8,11$ & VI \\
\hline 9 & $2,3,5,7,9,10$ & $1,2,3,4,6,8,9,11$ & $2,3,9$ & IV \\
\hline 10 & $2,3,5,7,10$ & $1,2,3,4,6,8,9,10,11$ & $2,3,10$ & III \\
\hline 11 & $1,2,3,5,6,7,8,9,10,11$ & $1,4,6,8,11$ & $1,6,8,11$ & VI \\
\hline
\end{tabular}

\section{FORMATION OF THE ISM-BASED MODEL}

A structural model named diagraph is developed based on the final reach ability matrix [8]. After removal of the transitivity links and replacement of the node information by statements, the ISM model is generated which has been shown in Figure 1. It has been practical from figure that 'Top level supervision commitment' has been very important inconsistent for Industry 4.0 realization in the Indian agriculture industry as it comes at the base of the ISM hierarchy [9].

\section{VII.CONCLUSION}

Indian agricultural industry sector is in high need to improve its competitiveness to sustain in the global market and to cope up with customer requirements. For gaining this goal, implementation of industry4.0 is the most probable solution. In this study, we have made a contribution in identifying the significant enablers using literature survey and industrial survey.Then the enablers are ranked on basis of their dependence and driving power using ISM methodology.After the research the Indian agricultural industries can identify where Industry 4.0 can be introduced and how to make smart solutions based on internet of things, visual computing, big data etc.

\section{REFERENCES}

1. Kang HS, Lee JY, Choi S, Kim H, Park JH, Son JY, Kim BH, Do Noh S. "Smart manufacturing: Past research, present findings, and future directions," International Journal of Precision Engineering and ManufacturingGreen Technology. 2016 Jan 1;3(1):111-28.

2. Valdeza A.C, Braunera P, Schaara AK, Holzingerb A, Zieflea M. Reducing complexity with simplicity-usability methods for industry 4.0. InProceedings 19th triennial congress of the IEA 2015 Aug (Vol. 9, p. 14). 
3. Sethuramalingam, T. K., and B. Nagaraj. "A soft computing approach on ship trajectory control for marine applications." ARPN J Eng Appl Sci 10, no. 9 (2015): 4281-4286.

4. Kagermann H, Helbig J, Hellinger A, WahlsterW. Recommendations for implementing the strategic initiative INDUSTRIE 4.0: Securing the future of German manufacturing industry; final report of the Industries 4.0 Working Group. Forschungsunion; 2013.

5. Yan J, Meng Y, Lu L, Li L. Industrial Big Data in an Industry 4.0 Environment: Challenges, Schemes, and Applications for Predictive Maintenance. IEEE Access. 2017; 5:23484-91.

6. Balakrishnan, Nagaraj, and K. Nisi. "A deep analysis on optimization techniques for appropriate PID tuning to incline efficient artificial pancreas." Neural Computing and Applications (2018): 1-10.

7. Zezulka F, Marcon P, Vesely I, Sajdl O. Industry 4.0-An Introduction in the phenomenon. IFAC-PapersOnLine. 2016 Jan 1;49(25):8-12.

8. Hermann M, Pentek T, Otto B. Design principles for industry 4.0 scenarios. In System Sciences (HICSS), 2016 49th Hawaii International Conference on 2016 Jan 5 (pp. 3928-3937). IEEE.

9. Atzori L, Iera A, Morabito G. The internet of things: A survey. Computer networks. 2010 Oct 28;54(15):2787805

10. Sushil, Interpreting the Interpretive Structured Model, Global Journal of Flexible System Management, 2012. 